University of Nebraska - Lincoln

DigitalCommons@University of Nebraska - Lincoln

Faculty Publications: Department of Entomology

Entomology, Department of

6-7-2008

\title{
A Review of the Genus Chortophaga (Orthoptera: Acrididae) Among Nebraska Populations: Questioning the Validity of Chortophaga australior Rehn and Hebard
}

\author{
Mathew L. Brust \\ University of Nebraska-Lincoln, mbrust@csc.edu \\ W. Wyatt Hoback \\ University of Nebraska at Kearney, whoback@okstate.edu \\ Robert J. Wright \\ University of Nebraska-Lincoln, rwright2@unl.edu
}

Follow this and additional works at: https://digitalcommons.unl.edu/entomologyfacpub

Part of the Entomology Commons

Brust, Mathew L.; Hoback, W. Wyatt; and Wright, Robert J., "A Review of the Genus Chortophaga (Orthoptera: Acrididae) Among Nebraska Populations: Questioning the Validity of Chortophaga australior Rehn and Hebard" (2008). Faculty Publications: Department of Entomology. 159.

https://digitalcommons.unl.edu/entomologyfacpub/159

This Article is brought to you for free and open access by the Entomology, Department of at DigitalCommons@University of Nebraska - Lincoln. It has been accepted for inclusion in Faculty Publications: Department of Entomology by an authorized administrator of DigitalCommons@University of Nebraska - Lincoln. 


\title{
A review of the genus Chortophaga (Orthoptera: Acrididae) among Nebraska populations: questioning the validity of Chortophaga australior Rehn and Hebard
}

Accepted June 7, 2008

\author{
Mathew L. Brust, W. Wyatt Hoback, and Robert J. Wright
}

(MLB, RJW) Department of Entomology, Plant Industry Building, University of Nebraska-Lincoln, 202 Plant Industry Building, Lincoln, NE 68583. Email: mlbrust@csc.edu; rwright2@unl.edu

(WWH) Department of Biology, Bruner Hall of Science, University of Nebraska at Kearney, 905 W 25th Street, Kearney, NE 68849. Email: hobackww@unk.edu

\begin{abstract}
Chortophaga australior Rehn and Hebard (Orthoptera: Acrididae) is considered a species distinct from Chortophaga viridifasciata (DeGeer). Collections across Nebraska have shown that the characters used to separate these two species are inconsistent and that the average state of these characters appears to be related to the time of the season during which the adults are collected. Until further study clarifies the status of $C$. australior, we suggest that its specific status be considered questionable.
\end{abstract}

\section{Key words}

Chortophaga, species, Nebraska, seasonal phenotype

\section{Introduction}

Chortophaga viridifasciata (DeGeer) (Orthoptera: Acrididae) is a common grasshopper which occurs across much of North America. Its known range extends from New Brunswick and Georgia west to Arizona, central Saskatchewan, and southeastern British Columbia (Otte 1984). It occurs in a wide variety of habitats including roadsides, meadows, pastures, lawns, and moist swales (Otte 1984), preferring areas where the soil contains a moderate amount of moisture (Blatchley 1920). Across most of its range it overwinters in the nymphal stage, mostly in the fourth and fifth instars (Otte 1984, Pfadt 2002).

Adults occur primarily in spring (mostly April to June in $\mathrm{Ne}$ braska), and exclusively in spring and early summer in the northern parts of its range (Brooks 1958, Kirk and Bomar 2005). However, adults have been collected as far north as South Dakota into September (Hebard 1925) and into October from Iowa (Froeschner 1954). Adults can be found during the summer months in the southern United States and have been found throughout the year in the Flint Hills of Kansas (Otte 1984, Smith 1981). A possible second generation was reported in Kansas (Smith 1981), and a distinct second generation has been reported from Oklahoma (Coppock 1962).

Chortophaga australior Rehn and Hebard is recognized as a species closely related to $C$. viridifasciata and was first described in 1910 (Rehn and Hebard 1911[1910]). Its known range is limited to Florida and Georgia, and west to the southeastern corner of Texas. Like C. viridifasciata, it occurs in a wide variety of grassy habitats (Otte 1984). Unlike C. viridifasciata it occurs throughout the year across its entire range (Otte 1984), and adults have been found in every month in Florida (Squitier and Capinera 2002).

The taxonomy of $C$. viridifasciata has remained constant since its description; however, that of $C$. australior has been the subject of debate in the past. In the original description, Rehn and Hebard (1910) distinguished C. australior as having the median carina of the pronotum less keel-like, the angle of the caudal margin of the pronotum less acute, the fastigium broader, and being of a markedly different color pattern than C. viridifasciata. Blatchley (1920) recognized C. australior as a subspecies of $C$. viridifasciata and stated that upon examining many specimens of $C$. viridifasciata from between Indiana and Florida, that only one structural and color difference was consistent between the two forms. The author concluded that "australior is, at most, only a southern geographic race or variety of viridifasciata".

Otte (1970) recognized C. australior as a full species and compared the courtship behavior of C. viridifasciata and C. australior and found that the crepitation rate of males of $C$. australior was higher than that of C. viridifasciata. The author also found that the crepitations of the females were louder than those of $C$. viridifasciata. The specimens of C. australior used in Otte's study were from Gainesville, Florida, and those of C. viridifasciata were collected mostly from Washtenaw County, Michigan.

Differentiation of these two forms among collected specimens remains difficult despite useful diagnostic characters. Otte (1984) provides a key for separating the two species and lists five useful characters (Table 1 ). In addition, the author mentions other defining characters in his description of each species. One important character mentioned which will be discussed further, refers to the presence of an $\mathrm{x}$-shaped mark on the dorsal pronotum of brown forms of C. australior, a mark lacking in C. viridifasciata.

During extensive collecting across Nebraska from 2005 to 2007, Otte (1984) was used as the primary resource for identifying members of the subfamily Oedipodinae to species. While nearly all of the material collected in April and May readily keyed out to $C$. viridifasciata, specimens from later in the season tended to match more characters of C. australior, and a few of these late season specimens matched as many as four of the five characters listed for C. australior. This prompted further collection of members of this taxon during the summer months in order to obtain a large sample for comparison.

The study reported here used specimens in the USDA-APHIS collection in Lincoln, Nebraska, which were collected between 2005 and 2007. Specimens were examined using characters given in Otte (1984), analyzed for differences, and compared temporally.

\section{Materials and Methods}

Specimens examined in this study were obtained from sweep samples taken at rangeland sites across the western two-thirds of Nebraska, as well as from more extensive collections by the first author. Measurements of curated specimens were made visually and without magnification, with the exception of the concavity of 
Table 1. Characters used in the Otte's key (1984) to differentiate between adults of C. viridifasciata and C. australior.

\begin{tabular}{ll}
\hline \multicolumn{1}{c}{ Characters of C. australior } & \multicolumn{1}{c}{ Characters of C. viridifasciata } \\
\hline \hline -Disk of pronotum with posterior margins usually forming & -Disk of pronotum strongly acute-angulate along posterior \\
almost right angle & margins \\
-Lateral field of forewings with strong dark marking directly bove & $\begin{array}{l}\text {-Lateral field of forewings without strong dark marking directly } \\
\text { base of hind femora }\end{array}$ \\
-Upove base of hind femora \\
knee), middle band distinctly triangular & -Upper face of hind femora not strongly banded and without \\
-Frontal ridge slightly concave at level of antennae & strong triangular mark in central part \\
-Hind tibiae bluish or blue-green & -Frontal ridge not concave at level of antennae \\
\hline
\end{tabular}

Table 2. Test of differences between characters from Otte (1984) against month of collection for Nebraska specimens of Chortophaga viridifasciata from, post-hoc tests. P-values are presented from Tukey tests following PROC GLM to detect significant differences (SAS Institute Inc. 1999). *Significant.

\begin{tabular}{lccccc}
\hline & \multicolumn{5}{c}{ Month } \\
Character & April & May & June & July & August + \\
\hline Caudal margin of pronotum & $0.0204^{*}$ & $<0.0001^{*}$ & 0.0943 & 0.1053 & 0.1579 \\
Forewing pattern & $<0.0001^{*}$ & $0.02325^{*}$ & 0.2830 & 0.3157 & 0.6315 \\
Hind femur markings & $<0.0001^{*}$ & $<0.0001^{*}$ & 0.1569 & 0.1579 & 0.4211 \\
Hind tibial color & $<0.0001^{*}$ & $0.0465^{*}$ & 0.3400 & 0.3684 & 0.5263 \\
\hline
\end{tabular}
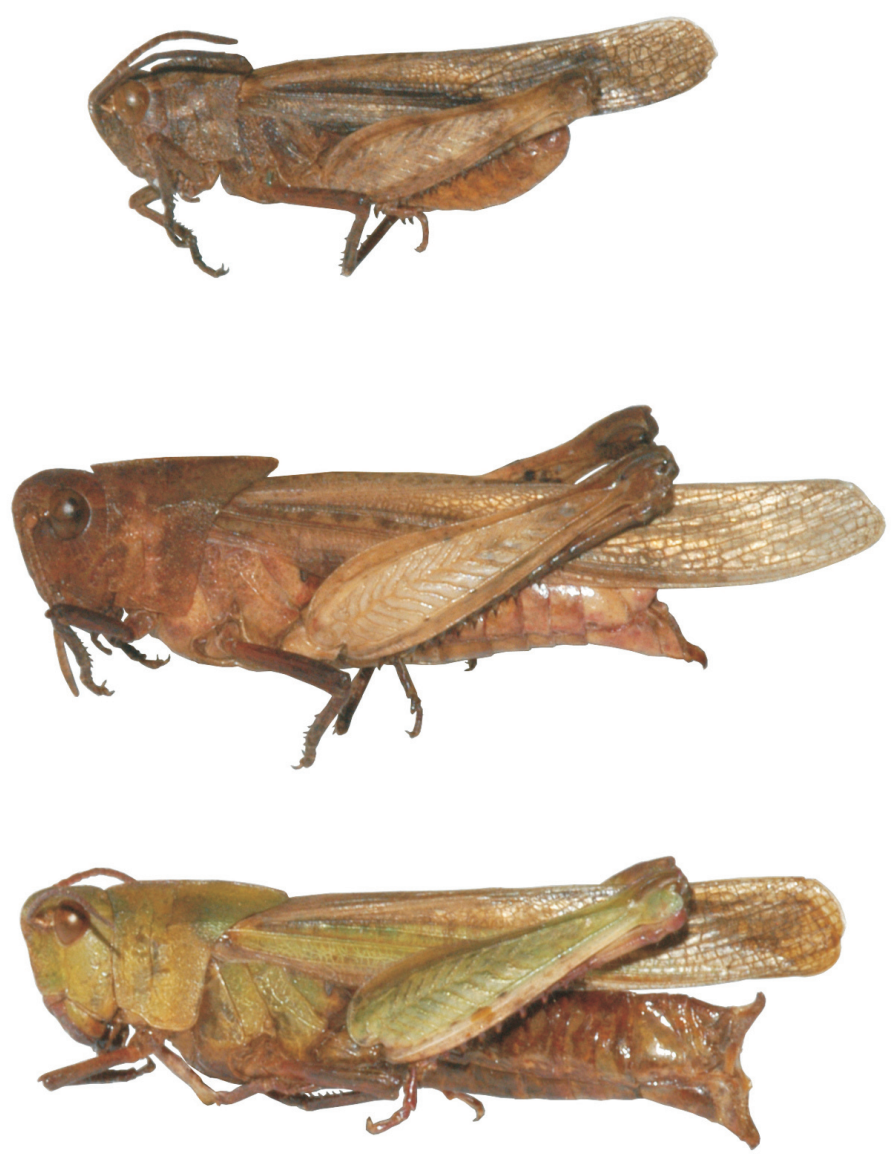

Fig. 1. Specimens representing typical C. viridifasciata $\left(\right.$ male $=1^{\text {st }}$ specimen, females $2^{\text {nd }}$ and $3^{\text {rd }}$ ). Note the lack of markings on the tegmina and hind femur, as well as the brownish to blackish hind tibiae. These specimens were collected in Lancaster County, Nebraska in April 2006. See Plate VII for color version.
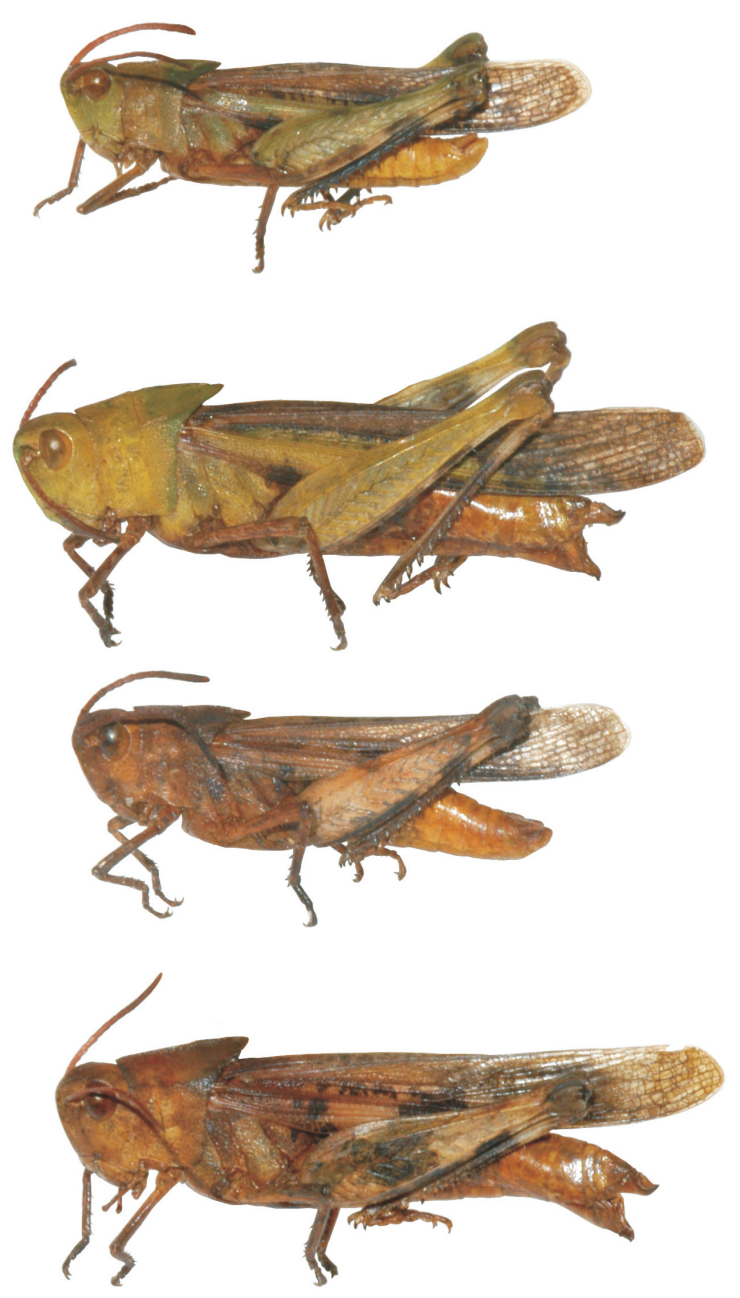

Fig. 2. Nebraska specimens sharing some characters with C. australior. Note the markings on the tegmina (all) and hind femur (top male; males $=1^{\text {st }}$ and $3^{\text {rd }}$ specimens, female $=2^{\text {nd }}$ and $\left.4^{\text {th }}\right)$, as well as the blue hind tibiae. These specimens were collected in Lancaster and Pawnee Counties in Nebraska in July 2006. See Plate VII for color version. 
Table 3. Percentage of Nebraska and Iowa adult specimens of C. viridifasciata matching a ratio of identifying characters used to separate this species from C. australior. Percentages to the right of " 2 of 5 " indicates the cumulative percentage that would be identified as $C$. australior using available literature.

\begin{tabular}{lccccccc}
\hline \multirow{2}{*}{ Month of Collection } & \multicolumn{6}{c}{$\%$ of specimens with \# of characters of C. australior } \\
\cline { 2 - 9 } & 0 of 5 & 1 of 5 & 2 of 5 & 3 of 5 & 4 of 5 & 5 of 5 & $\mathrm{n}$ \\
\hline April & $83.7 \%$ & $16.3 \%$ & $0 \%$ & $0 \%$ & $0 \%$ & $0 \%$ & 49 \\
May & $72.1 \%$ & $25.6 \%$ & $2.3 \%$ & $0 \%$ & $0 \%$ & $0 \%$ & 43 \\
June & $37.7 \%$ & $32.1 \%$ & $18.9 \%$ & $9.4 \%$ & $1.9 \%$ & $0 \%$ & 53 \\
July & $21.1 \%$ & $42.1 \%$ & $31.6 \%$ & $5.3 \%$ & $0 \%$ & $0 \%$ & 19 \\
August+ (Aug. to Oct.) & $15.8 \%$ & $15.8 \%$ & $36.8 \%$ & $21.1 \%$ & $10.5 \%$ & $0 \%$ & 19 \\
\hline
\end{tabular}

the frontal ridge, which was determined with a magnifying scope (Olympus SZ-STS) at 25X. A total of 184 specimens were examined, 181 of which were collected in Nebraska, with 3 collected in southwestern Iowa, less than $6 \mathrm{~km}$ from the Nebraska border. Each specimen was determined as fitting the characters given in Otte (1984) for either C. australior or C. viridifasciata. Those fitting C. viridifasciata were assigned a " 0 " and those fitting C. australior were assigned a " 1 ". One character was analyzed conservatively because the tibial color given in the key did not cover the variation seen in all specimens examined. Alarge number of specimens had distinctly black tibiae, which did not fit the characters given for either species. Those exhibiting black tibiae were thus assigned to C. viridifasciata in order that any associated error would be conservative.

The data were then analyzed with PROC GLM (SAS Institute Inc. 1999) using a binomial distribution. The characters used in Otte (1984) were employed as variables, and these were modeled against the month of collection. Because only a comparatively small amount of material was available from August to October, these three months were combined into a variable named "August+". When significant differences $(P<0.05)$ were found for a character across time, a post-hoc test (Tukey) was performed for comparisons between months.

\section{Results}

A large number of specimens in the collection of UDSA-APHIS in Lincoln, Nebraska, exhibit characters typical of C. australior (Figs 1 and 2). A small number (3) exhibit 4 of 5 characters used to differentiate these two species, and several (10) exhibit 3 out of 5 of these characters (Table 3). Based on our analyses, these trends appear to be related to seasonality (Fig. 3).

Of the five characters used to separate C. viridifasciata from C. australior, four showed significant differences among months of collection (Table 2). The only character which was distinctly not significant against month of collection was the concavity of the frontal ridge $(\mathrm{p}=0.7834)$. Our analyses suggest that 13 specimens from Nebraska and Iowa should be considered C. australior based on current identification methods.

Post-hoc tests showed several trends, all of which appeared to be related to month of collection (Table 2). Specimens collected from June to October were more likely to have the rear margin of the pronotum as a right angle, matching the character given for C. australior. Specimens collected from June to October were also more likely to exhibit a dark triangular mark on the tegmen near the base of the hind femur (with wings folded). Specimens collected from June to October were more likely to exhibit three distinct dark markings in the dorsal regions of the hind femur. Finally, specimens collected from June to October were more likely to exhibit blue to

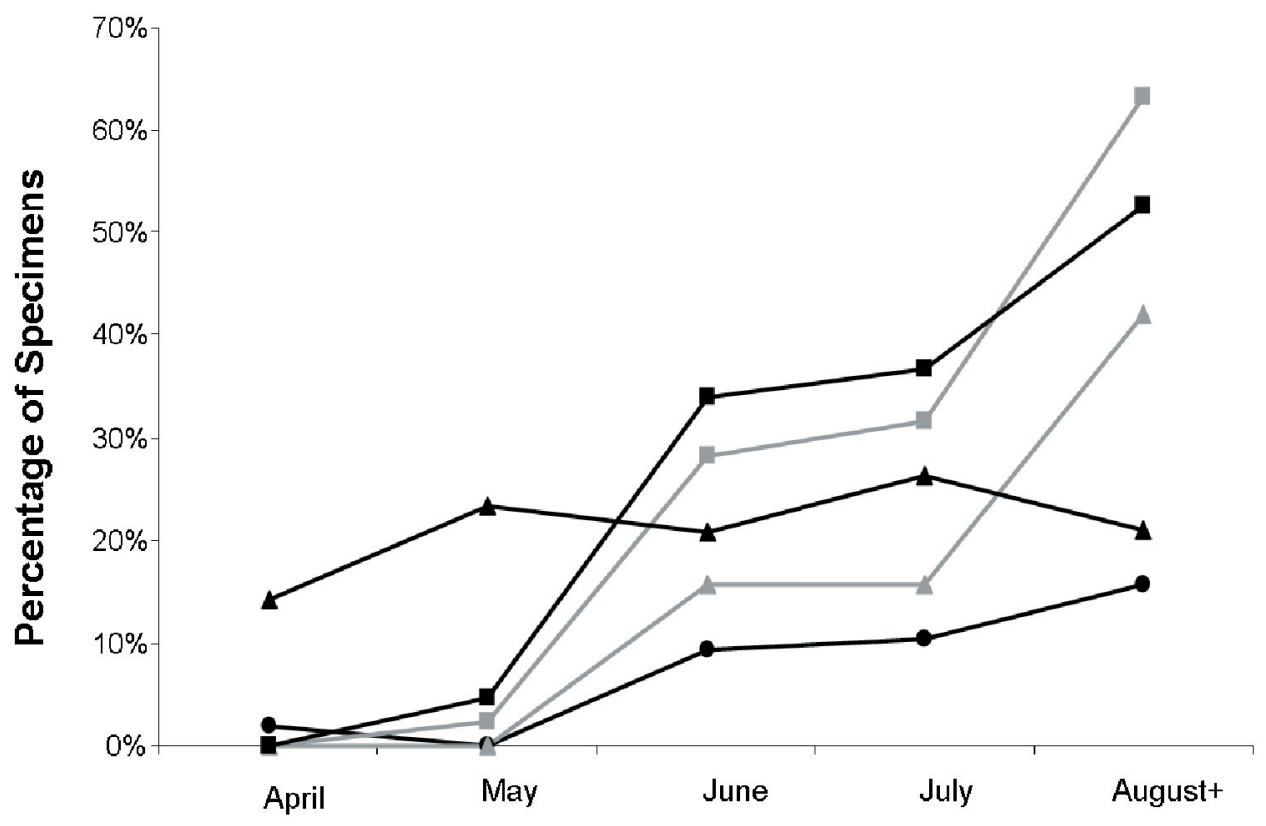

Month
Fig. 3. Percentage of Nebraska and Iowa adult specimens of $C$. viridifasciata matching an identifying character used to separate this species from C. australior by month of collection. Black square $=$ hind tibia blue, Black triangle $=$ frontal ridge concave at level of antennae, Black circle $=$ posterior edge of pronotum near right angle, Gray square $=$ forewings with dark marking at base of femur, Gray triangle = upper face of hind femur with three dark bands. 
blue-green hind tibiae than the dirty yellow or brown (or black in this case) typical of C. viridifasciata.

Our analysis suggests that the only character given in Otte (1984) that might consistently separate C. viridifasciata and C. australior is the concavity of the frontal ridge and that all other characters may differ among individuals of $C$. viridifasciata depending on the time in which the adults were active.

\section{Discussion}

This study indicates that the current methods used to differentiate between C. viridifasciata and C. australior are inadequate. The only alternative to considering some Nebraska material as matching $C$. australior, is to only consider material that matches all five characters as C. australior. While this would mean all Nebraska material matched C. viridifasciata, it would be a biased determination. From the standpoint of identification by key, it is necessary to have the key targeted toward not knowing what the specimen is likely to be and to make determinations based on majority rules. In addition, as we have not examined material from the known range of $C$. australior, we do not know if material from Florida would consistently match all five characters. Thus, if these are the most consistent characters allowing these two species to be differentiated, the validity of $C$. australior is questionable.

Our results suggest that one of several things may be occurring: 1) C. australior is not a valid species but rather a clinal or seasonal variant of $C$. virdifasciata, 2) that $C$. australior is a distinct and perhaps cryptic species, but with a much broader range than previously believed, or 3) C. australior represents a subspecies with an enormous breadth of geographic overlap with the nominate form. Other possibilities such as summer dispersal of $C$. australior or the presence of an extensive hybridization zone seem unlikely.

The characters presented in Otte (1984) are distinct enough that potential intermediate forms were almost nonexistent. In the rare cases that a single character was intermediate, species assignment was made based on either the pronotal disk or markings on the forewings. A specimen was assigned to C. australior if the posterior margin of the pronotal disk exceeded $90^{\circ}$, or if distinct dark marking occurred on the lateral field of the forewings just above the base of the hind femora. For the remaining three characters, the description is definitive enough that intermediate forms were not found.

Otte (1984) mentioned an x-shaped marking present on the dorsal pronotum of males of $C$. australior. While this was not included in his diagnostic key, it might be a useful character. However, three Nebraska specimens ( 2 males, 1 female) also exhibited this character. Thus, it appears that based on the current literature available, there is no single morphological character that can reliably allow C. australior and C. viridifasciata to be differentiated. While the shape of the posterior edge of the pronotum appeared to be the best differentiating character, even it did not always exclude $C$. australior.

Otte (1970) found distinct differences in courtship behavior between C. viridifasciata and C. australior. However, the locations from which individuals were collected for comparison of behavioral differences are very distant. Additionally, the author did not do a direct test of the acceptance of males by females of the two different forms. Blatchley (1920) points out that there is broad overlap in morphological characters in this taxon between Indiana and Florida. It might thus be hypothesized that if courtship behavior were observed from intervening populations, such as those found in Indiana or Tennessee, intermediate behaviors would have also been observed. Furthermore, it cannot be ruled out that if C. australior represents a seasonal form of $C$. virdifasciata, then courtship behaviors could differ based on season. If confirmed, this might represent an interesting line of study, particularly in the fields of genetics and evolution. For example, if broods in states such as Nebraska are largely nonoverlapping in the adult stage and the eggs from the late season adults overwinter, there may be very limited gene flow between broods.

The morphological differences noted in this study could be the result of environmental factors. For example, Otte and Williams (1972) found that environmental conditions affected whether nymphs occurred in the green or brown phase and that the amount of water present in the vegetation on which the nymphs fed was positively correlated with green-phase nymphs in C. viridifasciata. Whiting (1915) found that high humidity and low temperatures favored green adults and low humidity and high temperatures favored brown adults in this species. These studies suggest that $C$. viridifasciata is a highly variable species with an appearance that can be affected by environmental conditions.

There is also the potential that the changes in characters seen during the season in this study may be the result of northward dispersal by C. australior during the summer months. However, this possibility seems unlikely because even much larger species that overwinter farther north [e.g., Schistocerca americana (Drury)] are only rarely collected in Nebraska (Hauke 1953).

Our study is based on specimens from a very limited geographical region of the United States. However, it shows that characters from a variety which occurs over 1,000 km away can be shared with local populations, and that if the current traits used to differentiate C. viridifasciata and C. australior are considered the most useful, the status of $C$. australior should be questioned. Direct behavioral studies or genetic studies on this group are warranted.

\section{Acknowledgments}

We would like to thank Steve Johnson at USDA-APHIS for supporting the collection of specimens that led to this study, and Glen Salsbury at the Kansas State Department of Agriculture for verification of similar trends in Kansas. This is contribution number 1294 from the Department of Entomology, University of Nebraska-Lincoln.

\section{Literature Cited}

Blatchley W.S. 1920. Orthoptera of Northeastern America, with especial reference to the faunas of Indiana and Florida. The Nature Publishing Company, Indianapolis, IN. $784 \mathrm{pp}$.

Brooks A.R. 1958. Acridoidea of southern Alberta, Saskatchewan and Manitoba (Orthoptera). Canadian Entomologist 90: Supplement 9: $1-92$

Coppock S. Jr. 1962. The grasshoppers of Oklahoma. Oklahoma State University Agriculture Experiment Station Bulletin, Processed Series P-399: 1-141.

Froeschner R.C. 1954. The grasshoppers and other Orthoptera of Iowa. Iowa State College of Science 29: 163-354.

Hauke H.A. 1953. An annotated list of the Orthoptera of Nebraska, Part II, The Tettigidae and Acrididae. Bulletin of the University of Nebraska State Museum 3: 1-79.

Hebard M. 1925. The Orthoptera of South Dakota. Proceedings of the Academy of Natural Sciences, Philadelphia 77: 35-155.

Kirk K., Bomar C.R. 2005. Guide to the grasshoppers of Wisconsin. Bureau of Integrated Science Services, Wisconsin Department of Natural Resources, Madison, WI. $154 \mathrm{pp}$. 
Otte D. 1970. A comparative study of communicative behavior in grasshoppers. Museum ofZoology, University of Michigan, Miscellaneous Publication No. 141: 1-169.

Otte D. 1984. The North American Grasshoppers, Volume II, Acrididae: Oedipodinae. Harvard University Press, Cambridge, MA. 366 pp.

Otte D., Williams K. 1972. Environmentally induced color dimorphisms in grasshoppers, Syrbula admirabilis, Dichromorpha viridis, and Chortophaga viridifasciata. Annals of the Entomological Society of America 65: 11541161.

Pfadt R.E. 2002. A field guide to common western grasshoppers. 3rd edition. Wyoming Agricultural Experiment Station. Bulletin 912: 1-288.

Rehn J.A.G., Hebard M.. 1911[1910]. Records of Georgia and Florida Orthoptera, with the description of one new species and one new subspecies. Proceedings of the Academy of Natural Sciences, Philadelphia 62: 585-598.

SAS Institute Inc. 1999. The GLM procedure. SAS Institute Inc., Cary, North Carolina, USA.

Smith S. 1981. Variation in morphology and coloration among grasshoppers related to geographical distribution, seasonal occurrence, and plant communities in the flint hills region of Kansas. Ph.D. dissertation, Kansas State University. 217 pp.

Squitier J.M., Capinera J.L. 2002. Observations on the phenology of common Florida grasshoppers (Orthoptera: Acrididae). Florida Entomologist 85: 227-234.

Whiting P.W. 1915. Notes on some experiments on color changes in Chortophaga viridifasciata. Entomological News 26: 239. 